\title{
The radiation-sensitizing effect of flavopiridol in the esophageal cancer cell line Eca109
}

\author{
YUAN YAO, JINGBIN SHI, ZHUO ZHANG, FENG ZHANG, RUILAN MA and YAN ZHAO \\ Department of Radiology, The Second Hospital of Dalian Medical University, Dalian 116000, P.R. China
}

Received November 2, 2012; Accepted February 5, 2013

DOI: $10.3892 / 01.2013 .1291$

\begin{abstract}
Flavopiridol is a cyclin-dependent kinase inhibitor. It has shown an antitumor effect against several cancers. In the present study, the radiation-sensitizing effect of flavopiridol was investigated in an esophageal squamous carcinoma cell line, Eca109. The growth inhibitory rate of Eca109 with flavopiridol was determined using the MTT and the radiosensitizing rate using clonogenic survival assays. The cell cycle distribution and the rate of apoptosis were measured using flow cytometry. The proteins cyclin D1, ERK/pERK, caspase-3, Bax and Bcl-2 were detected using western blot analysis to elucidate the mechanism of the radiosensitization effect. MTT assay showed that flavopiridol inhibited the survival rate of Eca109 cells and the effect was dose-dependent. Its $\mathrm{IC}_{50}$ was $193.3 \mathrm{nmol} / \mathrm{l}$. The result of the clonogenic survival revealed that flavopiridol enhanced the radiosensitivity of Eca109 cells and the sensitization enhancement ratio (SER) was 1.194 at $0.2 \times \mathrm{IC}_{50}$. Moreover, we detected that the cells treated with flavorpiridol were arrested at the $G_{2} / M$ phase and the apoptosis caused by radiation was increased. In addition, the proteins caspase- 3 and Bax in cells treated with flavopiridol were upregulated, while cyclin D1 and Bcl-2 were downregulated. In conclusion, flavopiridol may enhance the radiosensitivity of Eca109 cells and the radiosensitizing effect of flavopiridol may be mediated by decreasing the levels of the cyclin D1 protein, thus increasing the percentage of cells at $\mathrm{G}_{2} / \mathrm{M}$ phase.
\end{abstract}

\section{Introduction}

Esophageal cancer is a common digestive malignancy. The latest statistics from the GLOBOCAN project from the World Health Organization (WHO) showed that 482,000 new cases and 407,000 mortalities worldwide in 2008 were of this type.

Correspondence to: Professor Jingbin Shi, Department of Radiology, The Second Hospital of Dalian Medical University, 467 Zhongshan Road, Liaoning, Dalian 116000, P.R. China

E-mail: 1963sjb@163.com

Key words: flavopiridol, apoptosis, cell cycle, radiation-sensitizing, esophageal cancer
The mortality rate was $84.4 \%$ (1) Esophageal cancer has become one of the most threatening malignancies to human health. Generally, radiotherapy and chemoradiotherapy using conventional chemotherapy agents are effective against esophageal squamous cell carcinoma (2). However, the 5-year survival rate is not satisfactory. A more effective chemotherapy agent with radiosensitizing effects requires development.

Research showed that a cell's relative radiosensitivity is determined by the cell cycle phase. Cells are most radiosensitive in the $G_{2} / M$ phase, less sensitive in the $G_{1}$ phase and least sensitive during the latter part of the $S$ phase (3). Cell cycle regulatory proteins, including cyclins and cyclin-dependent kinases (CDKs), are not well-regulated in tumor cells $(4,5)$. Flavopiridol, a CDK inhibitor, which has recently entered clinical trials (6), has been shown to exert antitumor activity in preclinical tumor models $(7,8)$.

Flavopiridol is a synthetic flavone (5,7-dihydroxy-8-(4-Nmethyl-2-hydroxypyridyl)-6'-chloroflavone hydrochloride), which is structurally related to a compound derived from the plant Dysoxylum binectariferum, indigenous to India and used in Indian folk medicine (9). It inhibits the activity of all CDKs, but primarily CDK1, 2 and 4; thus, are arrested at the $G_{2} / M$ phase (10). Recently, several studies have confirmed that flavopiridol induces cell cycle arrest in a number of types of cancer $(11,12,13)$. Given this, flavopiridol may also regulate cycle distribution of Eca109 (a type of esophageal squamous carcinoma) and affect its radiosensitivity. The aim of this study is to assess whether flavopiridol enhances the radiosensitivity of Eca109 cells and to elucidate its mechanism in vitro.

\section{Materials and methods}

Cell lines and treatment. The human esophageal carcinoma cell line Eca109, provided by the Tumor Cell Library of the Chinese Academy of Medical Science, was used in this study. The study was approved by the Ethics Committee of The Second Hospital of Dalian Medical University, Dalian, China. The cell line was cultured in RPMI-1640 containing $10 \%$ fetal bovine serum (FBS) and $1 \%$ penicillin-streptomycin and maintained at $37^{\circ} \mathrm{C}$ in an atmosphere of $5 \% \mathrm{CO}_{2}$ and $95 \%$ room air.

Reagents. Flavopiridol (Sigma-Aldrich, St. Louis, MO, USA) was dissolved in DMSO to a stock concentration of $1 \mathrm{mg} / \mathrm{ml}$ and stored at $-4^{\circ} \mathrm{C}$. 
3-(4,5-Dimethylthiazol-2-yl)-2,5-diphenyltetrazolium bromide (MTT) assay. Cells were seeded in a 96-well plate and once attached they were treated with various concentrations of flavopiridol ranging from 0 to $517.5 \mathrm{nmol} / 1$. After $48 \mathrm{~h}$, the cells were stained with $2 \mathrm{mg} / \mathrm{ml}$ MTT, lysed in DMSO and the absorbance was read on an enzyme-labeling instrument at $540 \mathrm{~nm}$. Each concentration had 3 wells and the experiment was repeated in triplicate.

Clonogenic survival. Cells were trypsinized to single-cell suspension and 200 cells were seeded into each well of a six-well tissue culture plate. They were divided into 2 groups: radiation only (R) and flavopiridol with radiation (FR). Each group had 3 wells. After cells were assigned, group FR received flavopiridol (concentration $0.2 \times \mathrm{IC}_{50}$ ) and group $\mathrm{R}$ received DMSO. Graded doses of 0, 2, 4, 6 and 8 Gy of radiation were administered with a 6-MV X-ray. Colonies were stained with crystal violet 15 days after seeding, the number of colonies containing at least 50 cells was determined and the surviving fractions were calculated. This experiment was repeated in triplicate.

Flow cytometry. Cells were divided into 4 groups: flavopiridol only $(\mathrm{F})$, radiation only $(\mathrm{R})$, flavopiridol with radiation $(\mathrm{FR})$ and control (C). Cells in group F were cultured with flavopiridol for 48 h. Group R received 6 Gy radiation. Group FR also received $6 \mathrm{~Gy}$ radiation once the cells had been cultured with flavopiridol for $48 \mathrm{~h}$. Following radiation treatment, the cells were cultured for another day. The cells were washed with phosphate-buffered saline (PBS), collected with trypsinization, stained with propidium iodide (PI) for cell cycle analysis or Annexin V/PI for apoptotic analysis and analyzed using flow cytometry.

Western blot analysis. The treatment protocols were the same as for the flow cytometry assay. After treatment, the cells were collected and washed with PBS. They were lysed with extraction buffer. Cellular debris was cleared by centrifugation and the protein concentration was assessed using a BCA protein assay. An equal amount of protein was subjected to SDS-polyacrylamide gel electrophoresis and transferred onto a polyvinylidene difluoride (PVDF) membrane. The membranes were probed with primary and secondary antibodies. The proteins were visualized using enhanced chemiluminescence (ECL) in a dark room.

\section{Results}

MTT assay. The dose-dependent cytotoxicity of flavopiridol alone was determined using an MTT assay. Cells were incubated in the presence of gradient concentrations of flavopiridol (ranging from 0 to $517.5 \mathrm{nmol} / \mathrm{l}$ ) for $48 \mathrm{~h}$. Flavopiridol alone reduced cell survival and the effect was dose dependent (Fig. 1). Its $\mathrm{IC}_{50}$ was $193.3 \mathrm{nmol} / \mathrm{l}$.

Clonogenic survival. To determine the effects of flavopiridol on Eca109 radiosensitivity, a clonogenic survival analysis was performed. As shown in Fig. 2, the number of colonies was decreased with increasing irradiation dose in both groups ( $\mathrm{R}$ and FR). The number of FR group decreased more

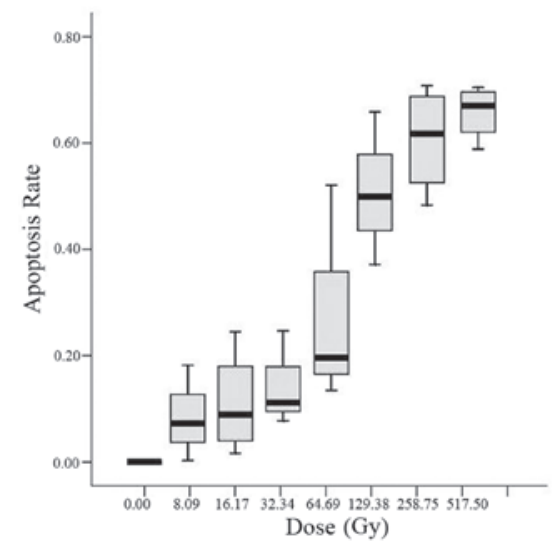

Figure 1. Survival rate of cells treated with gradient concentrations of flavopiridol (range, 0 to $517.5 \mathrm{nM}$ ) for $48 \mathrm{~h}$. Flavopiridol alone reduced cell survival and the effect was dose dependent.

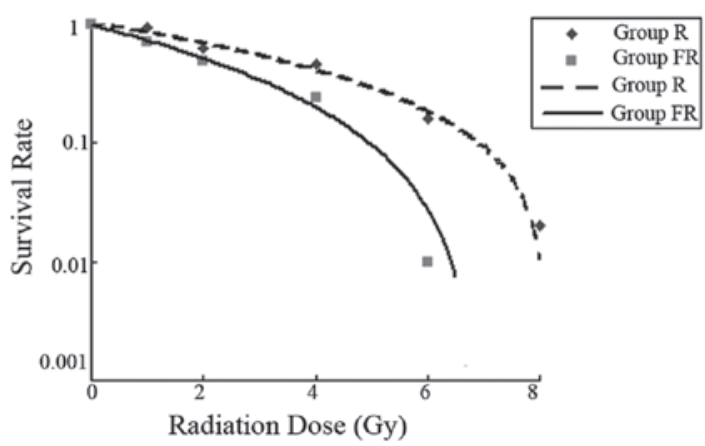

Figure 2. Survival fraction of cells treated with gradient FR and R. The number of clonies decreased with increasing irradiation dose in both $\mathrm{R}$ and FR. However, the number of FR decreased more significantly. R, radiation only; FR, flavopridol with radiation.

significantly. Flavopiridol enhanced the radiosensitivity of Eca109 cells. Multi-target single-hit model fitting survival curves resulted in a sensitization enhancement ratio (SER) of 1.194 .

Flow cytometry. To determine whether flavopiridol influences the cell cycle distribution of Eca109 cells, cells were treated as above and subjected to flow cytometry (Fig. 3). The percentage of $\mathrm{G}_{2} / \mathrm{M}$ cells in group FR $(29.18 \pm 9.26 \%)$ and group $\mathrm{F}(18.23 \pm 7.47 \%)$ was greater than that in groups $\mathrm{C}$ $(3.46 \pm 2.47 \%)$ and $\mathrm{R}(5.81 \pm 2.50 \%)$. The difference was statistically significant $(\mathrm{P}<0.05)$. The data suggested that a low dose of flavopiridol enhances the percentage of Eca109 cells in phase $\mathrm{G}_{2} / \mathrm{M}$ when treated by radiation.

Annexin V-FITC/PI apoptosis detection was used to determine whether flavopiridol enhanced apoptosis in Eca109 cells induced by radiation (Fig. 4). The control group showed $15.53 \pm 5.40 \%$ apoptosis, group F showed $15.50 \pm 7.95 \%$, group R showed $22.76 \pm 9.71 \%$ and group FR showed $37.92 \pm 16.15 \%$. The apoptosis rate in group FR was greater than that of the other three groups. The difference was statistically significant $(\mathrm{P}<0.05)$. The results revealed that flavopiridol enhances apoptosis in Eca109 cells induced by radiation. 

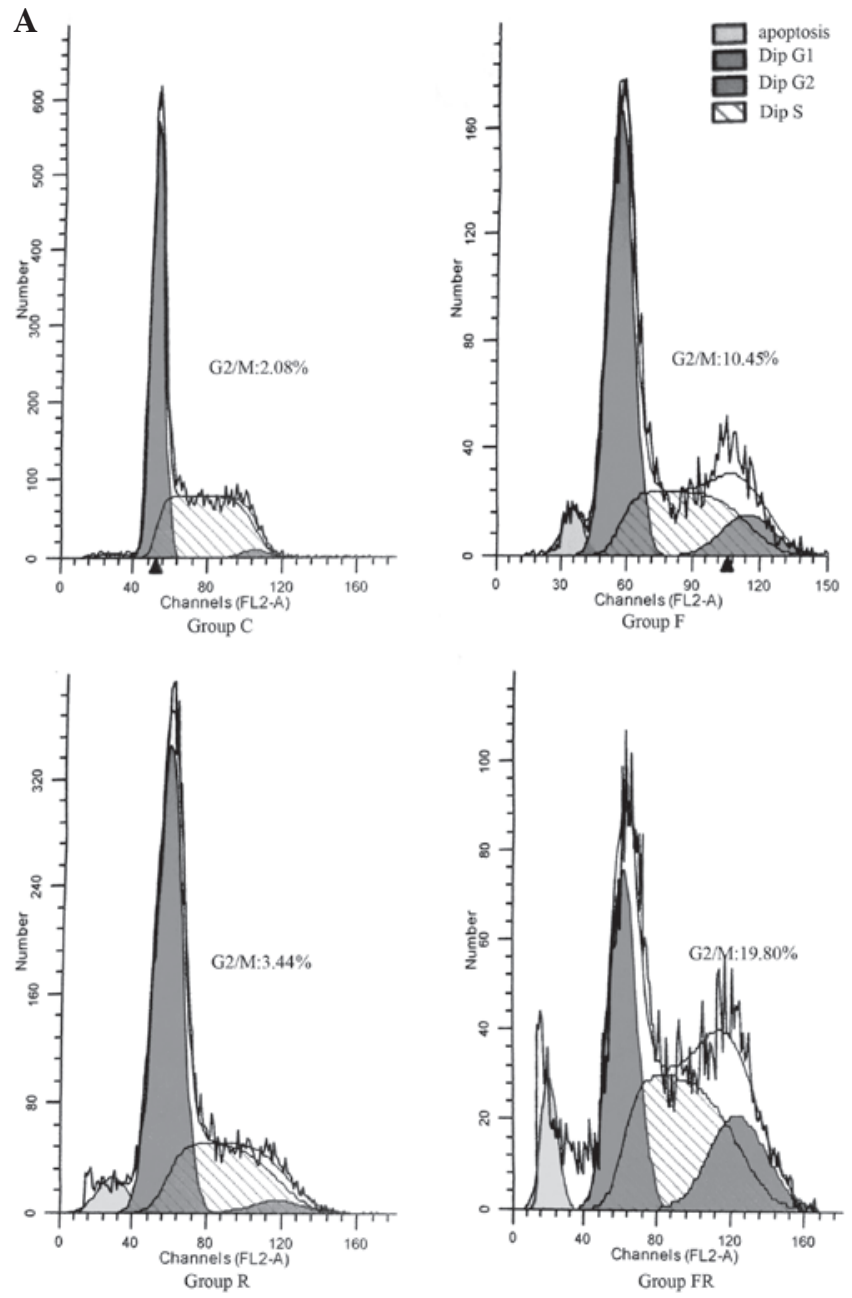

B

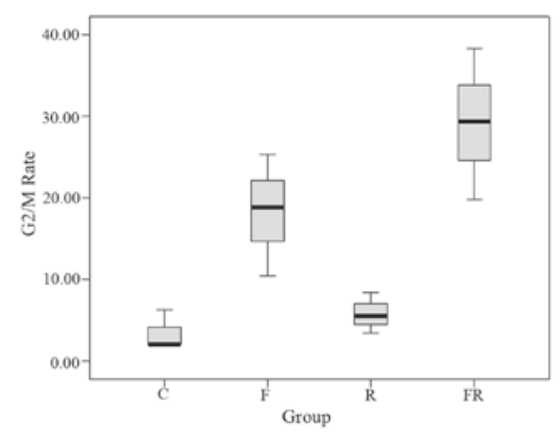

Figure 3. Cells of group F were cultured with flavopiridol for $48 \mathrm{~h}$. Group R received 6 Gy radiation. Group FR also received 6 Gy radiation after the cells had been cultured in flavopiridol for $48 \mathrm{~h}$. After radiation, the cells were cultured another day. Then the cells were washed with PBS, collected with trypsinization, stained with propidium iodide and analyzed (A) using flow cytometry. This experiment was conducted 3 times. (B) was calculated using SPSS 13.0. The phase G2/M of FR $(29.18 \pm 9.26 \%)$ and F $(18.23 \pm 7.47 \%)$ were greater than $\mathrm{C}(3.46 \pm 2.47 \%)$ and $\mathrm{R}(5.81 \pm 2.50 \%)$. The difference was statistically significant $(\mathrm{P}<0.05)$. C, control; F, flavopiridol; R, radiation only; FR, flavopiridol with radiation.

Western blot analysis. Caspase-3, Bax and Bcl-2 protein levels were measured to determine whether flavopiridol influences apoptosis proteins. As shown in Fig. 5A, the level of caspase-3 and Bax in group FR increased significantly and the level of $\mathrm{Bcl}-2$ in group FR decreased significantly. It is possible that cell death was caused by increasing levels of apoptotic
A
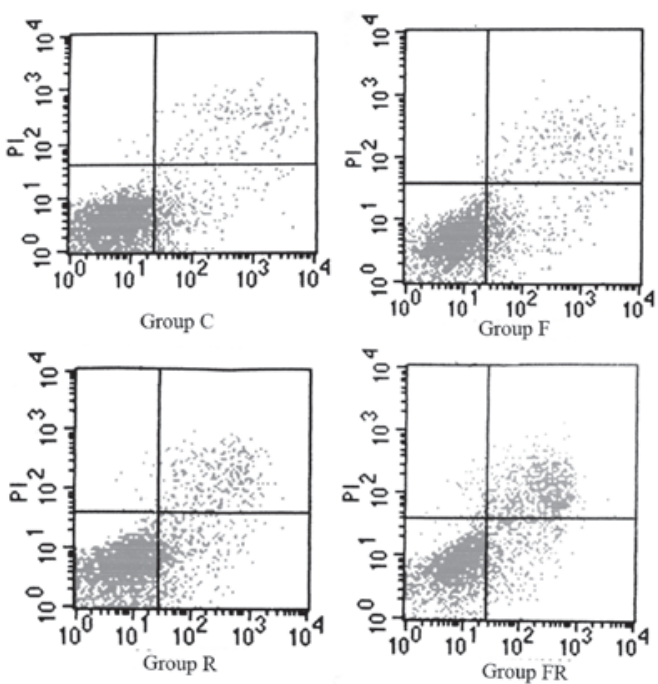

B

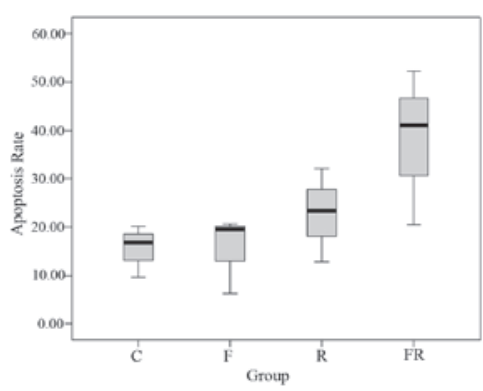

Figure 4. Cells of group $\mathrm{F}$ were cultured in flavopiridol for $48 \mathrm{~h}$. Group $\mathrm{R}$ received 6 Gy radiation. Group FR also received 6 Gy radiation after the cells had been cultured in flavopiridol for $48 \mathrm{~h}$. After radiation, the cells were cultured another day. Then the cells were washed with PBS, collected with trypsinization, stained with Annexin V/propidium iodide and (A) analyzed using flow cytometry. This experiment was conducted 3 times. (B) was calculated using SPSS 13.0. The group control showed $15.53 \pm 5.40 \%$ apoptosisi, F showed $15.50 \pm 7.95 \%$, R showed $22.76 \pm 9.71 \%$ and FR showed $37.92 \pm 16.15 \%$. The apoptosis of FR was evidently greater than the other 3 groups. The difference was statistically significant $(\mathrm{P}<0.05)$. C, control; F, flavopiridol; R, radiation only; FR, flavopiridol with radiation.

$\mathbf{A}$

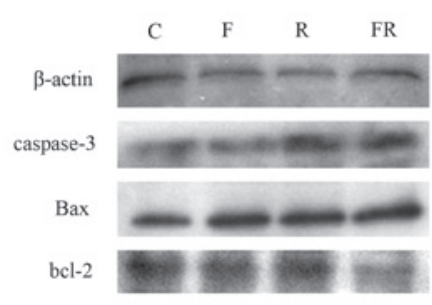

B
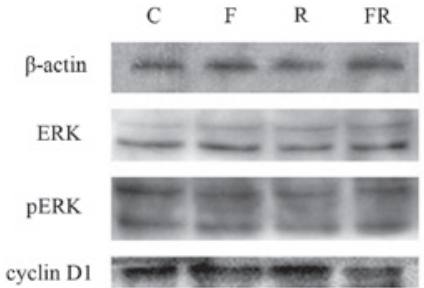

Figure 5. Western blotting analysis of (A) caspase-3, Bax and Bcl-2, and (B) cyclin D1, ERK and pERK, in Eca109 cell lines. The four groups were control (C), flavopiridol only (F), radiation only (R) and flavopiridol with radiation (FR). (A) The level of caspase-3 and Bax in FR increased significantly and the level of Bcl-2 in FR decreased significantly. (B) The level of cyclin D1 in FR was decreased significantly, while there was no significant difference in all groups about the level of ERK/pERK. 
proteins caspase-3 and Bax. Cyclin D1 protein was also detected to determine whether the increase in the percentage of Eca109 cells in phase $\mathrm{G}_{2} / \mathrm{M}$ was due to the decreased level of cyclin D1 protein. As shown in Fig. 5B, the level of cyclin D1 protein in group FR was significantly decreased. It suggested that flavopiridol enhanced phase $\mathrm{G}_{2} / \mathrm{M}$ in Eca109 by decreasing the level of cyclin D1 protein. ERK/pERK protein was detected to determine whether the Ras/Raf-1/Mek/ERK pathway was inhibited. The result was negative. The difference was statistically significant $(\mathrm{P}<0.05)$.

\section{Discussion}

From the present study, two conclusions may be drawn. Firstly, flavopiridol enhances the radiosensitivity of Eca109 cells. It increases the cell apoptosis induced by radiation. Secondly, the radiosensitizing effect of flavopiridol may be brought about by decreasing the level of cyclin D1 protein, thereby increasing the percentage of cells in the $\mathrm{G}_{2} / \mathrm{M}$ phase.

Cyclin D1 is overexpressed in several cancers $(14,15)$. It is also overexpressed in esophageal cancer (16). Cyclin D1 drives cells into the $\mathrm{S}$ phase. The trigger is likely to be assembly with its catalytic partners, CDK-4 and-6 (17). Flavopiridol decreases the level of cyclin D1, and according to Camphausen et al it also inhibits the activity of cdk-4 (10). Flavopiridol decreases the complex of cyclin D1 with CDKs. This may explain why $\mathrm{G}_{2} / \mathrm{M}$ arrest occurred. The transcriptional induction of cyclin D1 by growth factors is dependent on the Ras/Raf-1/Mek/ERK pathway (18-20). To elucidate whether flavopiridol reduced cyclin D1 by inhibiting this pathway, another western blot analysis for ERK/pERK was performed. There was no statistically significant difference. It was hypothesized that flavorpiridol decreases the level of cyclin D1 directly. The mechanism remains to be elucidated.

A cell's relative radiosensitivity is determined by the cell cycle phase. Cells are most radiosensitive in the $\mathrm{G}_{2} / \mathrm{M}$ phase, less sensitive in the $G_{1}$ phase and least sensitive during the latter part of the $S$ phase (5). Cell death was increased in the flavopiridol with radiation group. Caspase-3, Bax and Bcl-2 protein levels were investigated to elucidate the mechanism of cell death. Caspase is a family of proteases that is the core component of an intrinsic suicide machinery. Caspase- 3 is a type of effector caspase. It cleaves various cellular proteins leading to apoptotic cell death (21). All pathways to apoptosis converge on the activation of caspases. They may be classified into two types depending on whether they require Bcl-2 family proteins. Bcl-2 family members have been grouped into three classes. One class inhibits apoptosis (such as Bcl-2), the second class promotes apoptosis (such as Bax) and the third binds and regulates Bcl-2 proteins to promote apoptosis (22). Caspase-3 and Bax protein was increased significantly in cells treated with flavopiridol and radiation and Bcl-2 protein was significantly decreased. It may be hypothesized that flavopiridol promotes Bax and inhibits Bcl-2, thereby promoting caspase-3 to lead to apoptosis. This result was consistent with the flow cytometry result.

These in vitro data suggest that flavopiridol has radiosensitizing effects in Eca109 cells, but further investigation is required for in vivo tumor models. The mechanism also needs to be elucidated.

\section{Acknowledgements}

The authors would like to thank Professor Lu Shen (The Central Laboratory of The Second Hospital of Dalian Medical University, Dalian, China) for his helpful advice and discussion. They also thank Chen Yinghai and Zheng Jin for their excellent technical assistance.

\section{References}

1. Ferlay J, Shin HR, Bray F, Forman D, Mathers C and Parkin DM: GLOBOCAN 2008 v1.2, Cancer Incidence and Mortality Worldwide: IARC CancerBase No. 10 (Internet). International Agency for Research on Cancer, Lyon, France, 2010. http://globocan.iarc.fr. Accessed March 15, 2012.

2. Brown LM and Devesa SS: Epidemiologic trends in esophagealand gastric cancer in the United States. Surg Oncol Clin N Am 11: 235-256, 2002.

3. Pawlik TM and Keyomarsi K: Role of cell cycle in mediating sensitivity to radiotherapy. Int J Radiat Oncol Biol Phys 4: 928-942, 2004

4. MacLachlan TK, Sang N and Giordano A: Cyclins, cyclindependent kinases and cdk inhibitors: implications in cell cycle control and cancer. Crit Rev Eukaryot Gene Expr 5: 127-156, 1995.

5. Zafonte BT, Hulit J, Amanatullah DF, Albanese C, Wang C, Rosen E, Reutens A, Sparano JA, Lisanti MP and Pestell RG: Cell-cycle dysregulation in breast cancer therapies targeting the cell cycle. Front Biosci 5: 938-961, 2000.

6. Sedlacek HH: Mechanisms of action of flavopiridol. Crit Rev Oncol Hematol 38: 139-170, 2001.

7. Monga M and Sausville EA: Developmental therapeutics program at the NCI: molecular target and drug discovery process. Leukemia 16: 520-526, 2002.

8. Senderowicz AM and Sausville: Preclinical and clinical development of cyclin-dependent kinase modulators. J Natl Cancer Inst 92: 376-387, 2000.

9. Kaur G, Stetler-Stevenson M, Sebers S, Worland P, Sedlacek H, Myers C, Czech J, Naik R and Sausville E: Growth inhibition with reversible cell cycle arrest of carcinoma cells by flavone L86-8275. JNCI J Natl Cancer Inst 84: 1736-1740, 1992

10. Camphausen K, Brady K, Burgan W, Carra M, Russell J, Bull E and Tofilon P: Flavopiridol enhances human tumor cell radiosensitivity and prolongs expression of gammaH2AX foci. Mol Cancer Ther 3: 409-416, 2004.

11. Byrd JC, Shinn C, Waselenko JK, Fuchs EJ, Lehman TA, Nguyen PL, Flinn IW, Diehl LF, Sausville E and Grever MR: Flavopiridol induces apoptosis in chronic lymphocytic leukemia cells via activation of caspase-3 without evidence of bcl-2 modulation or dependence on functional p53. Blood 92: 3804-3816, 2008.

12. Patel V, Senderowicz AM, Pinto D, Igishi T, Raffeld M, Quintanilla-Martinez L, Ensley JF, Sausville EA and Gutkind JS: Flavopiridol, a novel cyclin-dependent kinase inhibitor, suppresses the growth of head and neck squamous cell carcinomas by inducing apoptosis. J Clin Invest. 102: 1674-1681, 1998.

13. Li Y, Bhuiyan M and Sarkar FH: Induction of apoptosis and inhibition of c-erbB-2 in MDA-MB-435 cells by genistein. Int J Oncol 15: 525-533, 1999.

14. Fredersdorf S, Burns J, Milne AM, Packham G, Fallis L, Gillett CE, Royds JA, Peston D, Hall PA, Hanby AM, Barnes DM, Shousha S, O'Hare MJ and Lu X: High level expression of p27kip1 and cyclin D1 in some human breast cancer cells: Inverse correlation between the expression of p27kip1 and degree of malignancy in human breast and colorectal cancers. Proc Natl Acad Sci USA 94: 6380-6385, 1997.

15. Gansauge S, Gansauge F, Ramadani M, Stobbe H, Rau B, Harada N and Beger HG: Overexpression of cyclin D1 in human pancreatic carcinoma is associated with poor prognosis. Cancer Res 57: 1634-1637, 1997.

16. Adélaide J, Monges G, Dérdérian C, Seitz JF and Birnbaum D: Esophageal cancer and amplification of the human cyclin $\mathrm{D}$ gene CCND1/PRAD1. Br J Cancer 71: 64-68, 1995.

17. Blagosklonny MV and Pardee AB: The restriction point of the cell cycle. Cell Cycle 1: 103-110, 2002. 
18. Filmus J, Robles AI, Shi W, et al: Induction of cyclin D1 overexpression by activated ras. Oncogene 9: 3627-3633, 1994.

19. Aktas H, Cai H and Cooper GM: Ras links growth factor signaling to the cell cycle machinery via regulation of cyclin D1 and the cdk inhibitor p27KIP1. Mol Cell Biol 17: 3850-3857, 1997.

20. Winston JT, Coats SR, Wang YZ and Pledger WJ: Regulation of the cell cycle machinery by oncogenic ras. Oncogene 12: 127-134, 1996.
21. Chang HY and Yang X: Proteases for cell suicide: functions and regulation of caspases. Microbiol Mol Biol Rev 64: 821-846, 2000.

22. Youle RJ and Strasser A: The BCL-2 protein family: opposing activities that mediate cell death. Nat Rev Mol Cell Biol 9: 47-59, 2008. 